January 2012

\title{
Scarcity and Abundance: Urban Agriculture in Cuba and the USA
}

\section{Andre Viljoen \& Katrin Bohn}

Across the world, urban agriculture has become an increasingly common feature of cities, responding to social, environmental and economic concerns. The vast majority of urban farmers produce fruit and vegetables within the city centre using organic principals. There is also an international upsurge of interest in water-based "aquaponic systems" combining traditional Chinese and Aztec fish farming principals with contemporary hydroponics; significant prototypes are appearing in many cities and as far afield as Brisbane and Milwaukee. Commercially viable schemes are not the only type of urban agriculture; in Europe we are very familiar with the "allotment type" of small personalised plots. Each type has distinct characteristics and benefits. Broadly speaking, commercial-scale production will be necessary if urban agriculture is to have a quantifiable impact on food production, whilst personalised production is very significant from a social and behaviour change perspective. It is generally acknowledged that urban agriculture will not meet all of a city's food needs, and any systematic review of urban food systems needs to consider relationships between a city, its local region and beyond.

Is Urban Agriculture a response to scarcity? To an extent it is: In modernising / developing societies in the global South it has often been seen as a response to crisis as evidenced by Cuba's introduction of urban agriculture after the collapse of its economy.However, more recently it is also being recognised as a way of preventing scarcity, i.e. by introducing closedloop no-waste cultivation systems into cities, while reducing food miles and providing heat island mitigation, visual amenity, public health and educational benefits - an an array of motives supporting sustainable urban development. In our 2005 book Continuous Productive Urban Landscapes (CPULS) ${ }^{1}$, we argue that urban agriculture should be integrated into city-wide networks of open space, providing a coherent and designed multifunctional landscape and that the benefits are significant enough to consider CPUL as essential sustainable urban infrastructure(Fig1). At the time, this proposition was seen as interesting though utopian, but since then the situation has changed dramatically to the extent that 
commentators have defined the Dutch City of Almere's future plans for Almere Oosterwold as a CPUL. ${ }^{2}$

\section{Context, scale, frugality and scarcity}

Absolute scarcity does not leave much room for design or indeed pleasure in the material world. After the collapse of the Soviet Union in the early 1990ies and due to the USA's trade blockade, Cuba experienced scarcity of almost all commodities including food. This was an extreme situation, and where there is no access to goods, there is severely restrained action and the trivial acquires significance, a broken kitchen tile remains broken and you see it every day.

We must differentiate between acting frugally in a society that is resource-rich and surviving in a situation of genuine scarcity. The general hope is that, when pending scarcity is recognised, we can use the remaining resources to construct robust infrastructures necessary to make the transition to a more sustainable future.

Agriculture is one of the few activities where, with few resources, such as harvested seeds, soil, rain, shared knowledge and labour, abundance can be created. Agriculture is also one of the most fundamental necessities for a settled community. In urban agriculture, scarcity and abundance can lie very close.

It is unsurprising that in post-1990ies Cuba, urban agriculture became established as part of an integrated food system. In response to food shortages, enterprising and able individuals started growing food for themselves on available land. Subsequently, the state embraced the concept of urban agriculture by setting up a comprehensive training and facilitation programme for would-be urban framers. Cuban urban agriculture is essentially organic, arising both from absolute scarcity with respect to chemicals (due to the trade blockade) and from pre-existing Cuban research into organic methods of pest control. An educated population meant that an internal knowledge and skills base could be deployed to creatively train new farmers and set up new soil based urban market gardens called organoponicos (Fig 1). At the same time, the USA blockade coupled with the collapse of the Cuban economy (scarcity) made it very difficult to undertake new technology-dependent research. 
Scarcity can make things obvious: Visiting Cuba in 2002 and witnessing fuel shortages put a lot of food miles theory into perspective. No fuel, no movement, bicycles and urban agriculture make sense. Nearly ten years later, and from an environmental perspective, urban farmers in Detroit are following the same principals. (Fig 2)

Cuba's urban agriculture is pragmatic: Criteria such as proximity of population and access to water are major factors determining location. Soil toxicity is less of an issue because the standard arrangement for urban agriculture plots uses raised beds that are quite easily isolated from toxic soil. Being placed pragmatically means that these sites effectively are urban design experiments, making the whole country a "laboratory for urban agriculture", whereby observations of the characteristics and qualities of these sites can be applied in other situations with a broader range of urban design implications to be considered. The spatial responses to scarcity begin to lead their own lives, and in so doing define a new urban typology.

Urban agriculture can contribute to the creation of multi-functional productive landscapes made of spaces that can be shared "visually" within a neighbourhood. How these fields are seen and perceived is significant, both with respect to perspective (height of the observer's eye) and the structure on the ground. Although not contrived to be ornamental, ornament is inherent within the visual patterns resulting from the functional layout of typical Cuban organoponicos. Parts of Tom Phillip's summary treatise "The Nature of Ornament", ${ }^{3}$ could have been written about any organoponico:

"8. Such universality (of ornament) is made possible by the relatively small generative syntax of ornament.

9. These syntactical elements are all paraphrases of nature; stripe, hatching, dot and the whole treasury of primal signs are all present in nature.

48. It stores our knowledge of the principles of growth and form (forking, branching, spiral) and diagramatises our experience."

Getting urban agriculture "written in" to planning documents is a critical enabling step everywhere in the world, and developing a public discourse that articulates its many benefits - from environmental motivation to ornament to behaviour change - is one of the 
actions required if urban agriculture is to be embedded in cities and rise to the challenge of proving its value beyond direct financial return.

Ten years on from our first observations in Cuba, their organoponicos remain and elsewhere, not least in the USA, urban agriculture experiments are testing out different scenarios. Baltimore, Milwaukee and Chicago are amongst a vanguard of North American cities actively encouraging urban agriculture. Recent discussions with planners and activists in the USA confirm our observation that practice is outstripping policy, as individuals take forward urban agriculture projects at a range of scales and with diverse aims. At the time of writing, one could say (if we grossly simplify the situation) that in Europe wider urban strategies, broadly in line with the CPUL City concept, are being developed, while in the USA a complete spectrum of pioneering individual projects are underway aiming to encompass and interlock desires for social gain, empowerment, community building, environmental improvement and commercial viability. The range of new projects is staggering, and if Cuba's urban agriculture revealed spatial possibilities and the effectiveness of systematic support systems, the USA is testing different spatial, technical and financial models of production.

In New York for example, alongside a long established radical and thriving community garden movement, new roof top farms are appearing. Predominantly established by mediasavvy young graduates and activists, these are pioneering projects whose participants through sheer hard work - are prototyping new, commercially viable food producing or educational enterprises. Across the USA, hydroponics and soil-based cultivation are being utilised for rooftop and covered (glass house) cultivation with much work occurring in Milwaukee, led by Will Allen's organisation "Growing Power" and developing practical aquaponic systems that integrate fish farming and hydroponics. Detroit's well publicised scarcity (of population as much as anything else) is resulting in numerous small scale urban agriculture initiatives and some very ambitious urban agriculture proposals for commercial and social enterprises. Detroit's Eastern (food) Market, under the direction of Dan Carmody who has a background in planning and development, provides one of the only public spaces in the city and is becoming the hub for a number of urban agriculture and open space initiatives with the potential to coalesce into a CPUL space giving coherence to a significant area of Eastern Detroit. 
Even though practice might be outstripping policy, policy is catching up, and both have to work together. The London Assembly's Planning and Housing Committee's investigation into the role of the planning system in supporting commercial food growing in London is typical of international trends,:"Our report Cultivating the Capital ${ }^{4}(2010)$ calls for changes to the planning system to......encourage food growing in London".

If urban agriculture continues to develop at the same rate as it has over the last decade, all the indications are that it has the opportunity now to anticipate scarcity, and if the economic and social infrastructure can be put in place to support it, we could build something far more abundant and significant than that envisaged by a romantic notion of "growing your own".

Urban agriculture might then answer scarcity by offering more experience with less consumption. 


\section{References.}

1. Andre Viljoen (editor), Continuous Productive Urban Landscapes: designing urban agriculture for sustainable cities, Architectural Press (Oxford), 2005.

2. J. E. Jansma and A.J. Visser, Agromere: Integrating urban agriculture in the development of the city of Almere, Urban Agriculture Magazine (Leusden) Number 25, 2011, pp.28-31. 3. Tom Phillips, The Nature of Ornament: A summary Treatise, Architectural Review (London), Vol CCXIII No 1274, 2003.

4. The London Assembly, Cultivating the Capital: Food growing and the planning system in London. The London Assembly (London), 2010.

Images and captions:

All images copyright Bohn\&Viljoen Architects

\section{Photos, CPUL space. Composite image.}

The CPUL City Concept: Continuous Productive Urban Landscapes (CPULs) are coherent networks of public open space made through the superposition of agricultural productivity and urban conviviality. The Cuban organoponico Pueblo Grifo Nuevo in Cienfuegos (left) exemplifies the size of site necessary if urban agriculture is to have a meaningful impact on the supply of fresh fruit and vegetables. Bohn\&Viljoen Architects "Continuous Picnic" (right) created for the 2008 London Festival of Architecture illustrates a type of public space envisaged within the CPUL City.

\section{Photo, Rising Pheasant.}

Rising Pheasant Urban Farm, Detroit: hand cultivation, organic production, distribution by bike, and selling at Detroit's long established Eastern Market, characterises one type of emerging urban agriculture. Eastern Market is one of the few public spaces in the city and is becoming a catalyst for the development of a CPUL network, including a greenway and urban agriculture sites. 
Photo, Will Allen.

Will Allen, founder of Growing Power, Milwaukee: is highly regarded for his development of a socially responsible, highly efficient organic and low tech approach to growing. Having recognised the contribution that urban agriculture can make to improve the quality of urban life, city authorities are removing unnecessary barriers to its implementation.

Photo, Eagle Wharf composite image.

Eagle Wharf Rooftop Farm, Queens, New York: employing organic cultivation, this first generation rooftop farm has a high level of productivity. A destination for local residents it also provides educational and public health benefits.

\section{Photo, Sweetwater composite image.}

Sweetwater Organics, Milwaukee: is prototyping large scale urban aquaponics aiming to transform hydroponic cultivation into a closed-loop system by incorporating fish farming within the nutrient loop. Sweetwater Organics is described by its Co-Founder James Godsil as "a farm, a laboratory, a museum, with open doors from the start. It is so new we need all the help we can get".

Diagram, B\&V Urban Agriculture Curtain.

The Urban Agriculture Curtain, The Building Centre London: a prototype building-integrated hydroponic system designed by the authors. Urban agriculture can operate across a range of scales and locations; here the set quantity of produce was used directly within the Building Centre's cafe.

\section{Biographies:}

\section{KATRIN BOHN}

is an architect and guest professor at the Technical University in Berlin where she heads the department "City and Nutrition" at the university's Institute for Landscape Architecture and Environmental Planning (ILAUP). Since 1998, she also runs Bohn\&Viljoen Architects with André Viljoen, a small London-based architectural practice and environmental consultancy. 
Bohn\&Viljoen Architects have taught, lectured, published and exhibited widely on the design concept of CPUL [Continuous Productive Urban Landscape] which they contributed to the international urban design discourse in 2004.

\section{ANDRE VILJOEN}

is an architect and academic programme leader for undergraduate architecture at the University of Brighton. In1998, with Katrin Bohn, he set up Bohn\&Viljoen Architects, a small London-based architectural practice and environmental consultancy. His design research focuses on sustainable design, in particular the concept of Continuous Productive Urban Landscapes. He is currently working on two books, Sustainable Food Planning: evolving theory and practice, and with Katrin Bohn, The CPUL City: making urban agriculture happen! 